\title{
Ser/Thr Phosphatases: The New Frontier for Myeloid Leukemia Therapy?
}

\author{
Amanda M. Smith, Kathryn G. Roberts and Nicole M. Verrills \\ School of Biomedical Sciences, University of Newcastle and \\ Hunter Medical Research Institute, Newcastle, NSW, \\ Australia
}

\section{Introduction}

Myeloid leukemias are characterised by mutation and altered expression of a range of tyrosine kinases. Over $90 \%$ of chronic myeloid leukemias (CML) harbour the Philadelphia chromosome, resulting in expression of the BCR/ABL fusion protein, a constitutively active tyrosine kinase that is essential for survival of the CML cells. Acute myeloid leukemia (AML) is a heterogeneous disease characterised by mutations and dysregulation of a range of tyrosine kinases including the receptors Fms-like tyrosine kinase (Flt-3), c-KIT and platelet derived growth factor receptor (PDGFR). Tyrosine kinases represent powerful therapeutic targets, as the archetypical example of imatinib has shown for CML. However, many patients develop resistance to imatinib and other second generation inhibitors. Furthermore, trials of tyrosine kinase inhibitors for AML have thus far proven disappointing. Thus novel therapeutic targets are needed in order to improve the survival of myeloid leukemia patients.

Oncogenic tyrosine kinases induce activation of a variety of signaling pathways required for the growth and survival of leukemia cells, such as the Ras/MAPK, PI3K/Akt, and JAK/STAT pathways. In addition to protein kinases, the rate and duration of protein phosphorylation is tightly regulated by the activity of protein phosphatases, and in normal cells the reversal of protein phosphorylation by phosphatases is essential for providing the fine-tuning of signaling pathways and maintaining a balance in cellular physiology. While much of the focus for targeted therapies in leukemia therapy has concentrated on the kinases responsible for phosphorylation events, relatively little attention has been given to the role that protein phosphatases play. However, research over the past decade has now begun to highlight the importance of protein phosphatases in leukemia and their potential as targets for novel therapies. In particular, the ser/thr phosphatase PP2A has emerged as an important tumor suppressor in myeloid leukemias and strategies aimed at reactivating this complex enzyme show great promise for a new generation of leukemia therapies.

\section{Protein phosphorylation in cellular signaling}

Signal transduction via a network of cellular communication pathways enables modulation of essential cellular functions such as proliferation, differentiation, survival, adhesion, motility and death. Phosphorylation is the most common mechanism for the propagation of 
intracellular signals. The net phosphorylation state relies on a delicate balance between protein kinases, which catalyse phosphate addition, and protein phosphatases, catalysing phosphate removal. The role of protein kinases in the cellular signaling pathways controlling biological functions has been extensively studied and protein kinases are currently the pharmaceutical industry's second largest drug target (Cohen 2002). In contrast, the role of phosphatases in disease has only recently come to the forefront of research.

Proteins are primarily phosphorylated on Serine (Ser), Threonine (Thr) and Tyrosine (Tyr) residues, each accounting for approximately 86,12 and $2 \%$ of the human phosphoproteome respectively (Olsen et al. 2006). Around $2 \%$ of the human genome encodes a protein kinase gene, totalling 518 genes, of which 428 are known or predicted to phosphorylate Ser or Thr residues, and 90 encode protein tyrosine kinases (Alonso et al. 2004; Manning et al. 2002). In contrast, the human genome only encodes 147 phosphatase catalytic subunit genes. Of these, 107 encode a protein tyrosine phosphatase (PTP), a number that is comparable with the opposing tyrosine kinase genes (Alonso et al. 2004). Interestingly, while $98 \%$ of phosphoprotein sites are Ser and Thr residues, only a handful of the total protein phosphatases are specific for these amino acids (Moorhead et al. 2007). The unique way in which Ser/Thr phosphatases are regulated explains the difference in the number of Ser/Thr phosphatase catalytic subunits compared to PTPs. The evolution of PTPs has developed through the addition of discrete modular domains onto a core catalytic domain that define the function of the enzyme. In contrast, Ser/Thr phosphatases consist of a relatively simple catalytic subunit that reversibly binds to additional regulatory or interacting partner proteins which target the complex to specific subcellular locations and substrates, and ultimately control their activity.

\section{Classification of protein phosphatases}

Protein phosphatases can be classified into three main classes based on characteristics such as sequence, structure and phosphoamino-acid specificity. According to substrate specificity the largest phosphatase class is the ser/thr specific phosphoprotein phosphatase (PPP) family including PP1, PP2A, PP2B and PP4-PP7. The metallo-protein phosphatase dependant (PPM) family, made up mainly of PP2C, also functions against serine and threonine residues. Protein tyrosine phosphatases (PTP) form the second group and the aspartate-based or dual specificity protein phosphatases (DUSPs) the third. Genetic sequencing and analysis maintained these rules of partition, however it has recently been shown that particular Ser/Thr phosphatases can also dephosphorylate Tyr residues and various enzymes that fall into the dual specificity category based on their genetic sequence can selectively function on Ser, Thr, Tyr, phosphoinositides or RNA (Alonso et al. 2004; Begley and Dixon 2005).

\section{PTPs in myeloid leukemias}

The role of PTPs in cancer has been recently reviewed (Jiang and Zhang 2008; Julien et al. 2011; Lopez-Ruiz et al. 2011; Ruela-de-Sousa et al. 2011) and will not be discussed in detail here. However it should be noted that PTPs can act as either tumor suppressors or oncogenes in both solid tumors and leukaemais. For example, SHP1, a non-receptor PTP, displays tumor suppressive properties. SHP1 associates with a number of signaling molecules including CD5, the IL-3 receptor, CD22, the B-cell receptor, c-KIT and BCR/ABL 
(Bruecher-Encke et al. 2001; Lorenz et al. 1996; Zhang et al. 2000), and these interactions exert primarily inhibitory effects on the signaling pathways. Silencing of the SHP1 gene via promotor methylation has been identified as a common event in a range of leukemias and lymphomas, and has been suggested as a potential marker for disease progression (Chim et al. 2004; Johan et al. 2005; Oka et al. 2002; Zhang et al. 2000). Other PTPs implicated as tumor suppressors in myeloid leukemias include PTEN, PTPN2, DEP-1, and DUSP-16. In contrast, SHP2 displays oncogenic properties as it promotes growth and survival pathways due to its dephosphorylating activity toward negative regulators of the Ras/Erk and PI3K/Akt signaling pathways (Neel et al. 2003). Somatic mutations in the SHP2 gene occur in around $30 \%$ of sporadic juvenile myelomonocytic leukemia (JMML) cases (Tartaglia et al. 2003), 6\% of childhood acute lymphoblastic leukemia (ALL) (Tartaglia et al. 2004) and 5\% of AML (Bentires-Alj et al. 2004; Tartaglia and Gelb 2005; Tartaglia et al. 2004; Tartaglia et al. 2005). Other PTPs with potential oncogenic roles in leukemia include CD45, Cdc25, and DUSP-7.

\section{Ser/Thr phosphatases}

In the early 1980s Ingebritsen and Cohen utilised a number of characteristics of phosphatases to pioneer nomenclature classes for the various enzymes (Ingebritsen and Cohen 1983a). Biochemical assays, sensitivity to endogenous inhibitors and the limited knowledge of substrate specificity at the time were originally used to classify the Ser/Thr phosphatases as either type 1 (PP1) or type 2 (PP2). PP1 specifically dephosphorylates the $\beta$ subunit of phosphorylase kinase and is inhibited by nanomolar concentrations of the two small heat- and acid-stable proteins, termed inhibitor-1 (I-1) (Nimmo and Cohen 1978) and inhibitor-2 (I-2) (Foulkes and Cohen 1980). PP2 phosphatases preferentially dephosphorylate the a-subunit of phosphorylase kinase and are insensitive to I-1 and I-2 (Cohen 1989; Ingebritsen and Cohen 1983a; Ingebritsen and Cohen 1983b). PP2 phosphatases could in turn be subclassified into three distinct enzymes, PP2A, PP2B, and PP2C in a number of ways, but most simply by their metal-ion requirement. PP2A does not require a metal ion, however, $\mathrm{PP} 2 \mathrm{~B}$ and $\mathrm{PP} 2 \mathrm{C}$ are $\mathrm{Ca}^{2+}$ and $\mathrm{Mg}^{2+}$ dependent respectively (Ingebritsen and Cohen 1983a; Ingebritsen and Cohen 1983b; Moorhead et al. 2007). More recently the Ser/Thr phosphatases were re-defined according to their structurally distinct gene family as part of the phosphoprotein phosphatase (PPP) family comprising PP1, PP2A, PP2B, PP4, PP5, PP6 and PP7 catalytic subunits, or protein phosphatase $\mathrm{Mg}^{2+}$ or $\mathrm{Mn}^{2+}$ dependent (PPM) family primarily composed of the PP2C catalytic subunit. The majority of Ser/Thr phosphatase activity in vivo is accounted for by the PPP family members PP1, PP2A and PP2B, together with PP2C of the PPM family (Barford et al. 1998). In the majority of cases they operate in hetero-oligomeric complexes interacting with an increasing diversity of targeting and regulatory subunits (Gallego and Virshup 2005).

\section{Protein phosphatase 2A (PP2A)}

The past decade has seen a surge in research into the PPP family member, PP2A, most notably due to the discoveries indicating its important role as a tumor suppressor. In particular PP2A has been implicated as a major player in myeloid leukemias and as a potential target for novel therapeutic strategies. In order to study the role of PP2A in leukemogenesis, understanding the structure and function of this complex enzyme is imperative, and as such is summarised below. 


\subsection{Structure and regulation of PP2A}

PP2A is not a single phosphatase, but essentially encompasses a group of oligomeric enzymes consisting of a well conserved catalytic and structural subunit, together with the addition of one of a variety of regulatory subunits (Fig. 1). It makes up 1\% of total cellular proteins and along with PP1, accounts for over $90 \%$ of serine/threonine phosphatase activity in the cell (Eichhorn et al. 2009). The PP2A core enzyme consists of a structural subunit (PP2A-A/PR65) and a catalytic subunit (PP2Ac). In mammals, two distinct genes (a and $\beta$ ) encode closely related versions of both the A (Hemmings et al. 1990) and $C$ subunits (Arino et al. 1988). A third regulatory subunit (PP2A B) binds to the AC heterodimer, and determines both the substrate specificity and cellular localisation of PP2A holoenzyme complexes. Three B subunit families have been identified to date: B/B55/PR55 (Mayer et al. 1991; Strack et al. 1999; Zolnierowicz et al. 1994), B'/B56/PR61 (McCright et al. 1996; McCright and Virshup 1995), B"/PR72/130/PR70/48 (Hendrix et al. 1993; Stevens et al. 2003; Yan et al. 2000). Regulation of PP2A activity is accomplished primarily by members of its regulatory subunits. An additional level of regulation is introduced by post-translational modification of the catalytic subunit, which can undergo methylation and phosphorylation (Janssens et al. 2008), as well as the interaction with a vast array of other cellular and viral proteins such as SET, CIP2A and the SV40 small T antigen (Janssens and Goris 2001; Sablina and Hahn 2008). The use of specific PP2A inhibitors, PP2A activators and molecular genetics tools both in vitro and in vivo have exposed a role for PP2A in cell morphology, cell cycle regulation, development and apoptosis.

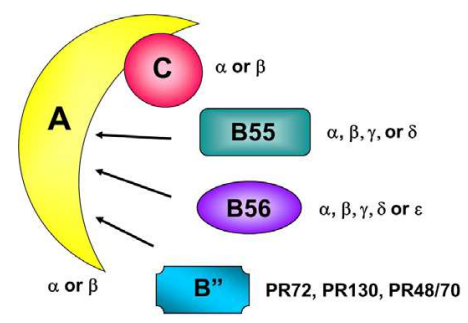

Fig. 1. Schematic of PP2A holoenzymes

\subsection{PP2A in cellular signaling}

PP2A has been implicated in a wide range of cellular signaling pathways, many of which are involved in cellular proliferation, apoptosis and differentiation, and as such are important in tumorigenesis. Since PP2A is one of the most abundant cellular phosphatases, it is not surprising that PP2A can exert opposing roles on similar pathways by acting at different levels. Recent work indicates that this substrate specificity is mediated by distinct PP2A complexes.

\subsubsection{PP2A and MAPK signaling}

A major function of PP2A is regulation of the MAPK signaling pathway. Interestingly, PP2A can exert both inhibitory and activating effects in a context-dependent manner (Fig. 2). PP2A acts negatively via the dephosphorylation of MEK (Heriche et al. 1997; Sontag et al. 1993) and ERK both in vitro and in mammalian cells (Alessi et al. 1995; Wang et al. 2003; Zhou et al. 2002). Specific knockdown of B56 $\beta$ and B56y, but not B55 family subunits in NIH3T3 mouse fibroblasts increases basal ERK activation and prolongs ERK signal during stimulation in the 
absence of pMEK (Fig. 3A) (Letourneux et al. 2006). More recent evidence indicates that PP2A activates Ras-dependent MAPK signaling at the level of Raf- 1 and its scaffolding protein Kinase Suppressor of Ras-1 (KSR1) (Abraham et al. 2000; Jaumot and Hancock 2001; Kubicek et al. 2002; Ory et al. 2003). Dephosphorylation of KSR1 (Ser329) and Raf-1 (Ser259) by B55a-containing PP2A complexes induces membrane translocation and increases the kinase activity of both proteins in several mammalian cell models, including NIH3T3, COS and HEK293 cells (Fig. 3B) (Abraham et al. 2000; Adams et al. 2005; Dougherty et al. 2005; Ory et al. 2003). Taken together, these studies provide biochemical mechanisms for how PP2A functions as a negative and positive regulator of MAPK signaling, depending on the specific regulatory subunit and substrate involved.

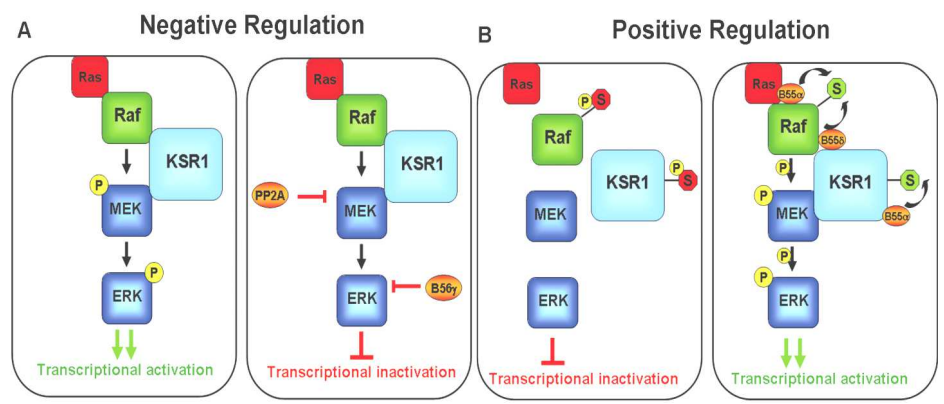

Fig. 2. Schematic overview of MAPK signaling regulation by PP2A

A) PP2A holoenzymes containing B56 family members negatively regulate MAPK signaling by inactivating MEK and ERK. B) In the inactive state, Raf and KSR1 are phosphorylated on Ser259 and Ser329, respectively, and are located within the cytoplasm. Upon stimulation, B55 $\alpha$-containing PP2A complexes dephosphorylate these residues, which results in protein activation and translocation to the plasma membrane. This facilitates the Ras/Raf interaction and induces transcriptional activation.

\subsubsection{PP2A and PI3K/Akt signaling}

The normal function of Akt is tightly modulated by phosphorylation events on Thr308 or Ser473 (Sarbassov et al. 2005; Vanhaesebroeck and Alessi 2000), and PP2A is the major phosphatase targeting these residues in vitro (Borgatti et al. 2003; Ivaska et al. 2002; Resjo et al. 2002). Over-expression of B55a-containing PP2A holoenzymes in the pro-lymphoid FL5.12 cell line substantially dephosphorylates Akt at Thr308 and results in subsequent growth suppression (Kuo et al. 2008). Conversely, Aa downregulation impairs Akt phosphorylation in neuronal cells, implicating PP2A as a positive regulator of the PI3K/Akt survival signaling cascade (Strack et al. 2004). An intriguing study by Andrabi et al., demonstrated that Akt can act as a pro- or anti-apoptotic protein depending on environmental stimuli, and this is governed by PP2A (Andrabi et al. 2007). The specific PP2A regulatory subunits controlling this apparent switch remain undefined; however, this study reinforces the importance of understanding PP2A regulated cell signaling in a context dependent manner.

\subsubsection{PP2A and Wnt/ $\beta$-catenin signaling}

The function of PP2A in Wnt/ $\beta$-catenin signaling is similar to its role in the MAPK pathway, with individual PP2A subunits exerting either positive or negative effects (Fig. 3). B56 
family members associate with APC (Seeling et al. 1999; Yamamoto et al. 2001) and axin (Hsu et al. 1999; Li et al. 2001) to impair Wnt signaling; a function that is critical for normal dorsal/ventral axis formation in Xenopus development (Li et al. 2001). Further studies demonstrate that association of the PP2A PR72 subunit with Naked cuticle is critical for the inhibitory function of this protein on the Wnt pathway (Fig. 3A) (Creyghton et al. 2005). PP2A is also an important positive regulator of Wnt signaling (Bajpai et al. 2004; Gotz et al. 2000; Ratcliffe et al. 2000; Willert et al. 1999). Loss of function analysis suggests that B56ع is required for Wnt-mediated development in Xenopus embryogenesis (Yang et al. 2003). Purified B55a-containing PP2A holoenzymes directly dephosphorylate $\beta$-catenin in vitro. Accordingly, specific knockdown of B55a in SW480 colon cancer cells significantly elevates $\beta$-catenin phosphorylation, which induces protein degradation and inhibits the Wnt pathway (Zhang et al. 2009). Surprisingly, PR130 opposes the action of PR72 and modulates Wnt signal transduction by restricting the ability of Naked to function as a Wnt inhibitor (Fig. 4B) (Creyghton et al. 2006). These studies illustrate an excellent example whereby specific PP2A regulatory subunits determine holoenzyme function and provide the fine control on important cellular processes.

\subsubsection{PP2A and $\mathrm{p} 53$ regulation}

The tumor suppressor, p53, plays a critical role in mediating cellular responses to various types of stress, such as DNA damage, by inducing growth arrest or programmed cell death. The stability and activity of p53 is regulated by phosphorylation which, under normal cellular growth conditions, targets the protein for proteasome-mediated degradation (Vogelstein et al. 2000). PP2A B56y holoenzymes dephosphorylate p53 on Ser37 (Dohoney et al. 2004) and Thr55 (Li et al. 2007) following Y radiation; an event which stabilises p53 in response to DNA damage and contributes to apoptosis in mammalian cells. Furthermore, ataxia-telangiectasia mutated (ATM) directly phosphorylates and specifically regulates B56 Y and B568. Phosphorylation of B56y3 at Ser510 after DNA damage increases B56ץ-PP2A complexes, and directs PP2A phosphatase activity toward p53, activating its tumorsuppressive functions (Shouse et al. 2010). Conversely, RNAi knockdown of B56y reduces p53 stability and inhibits cell death ( $\mathrm{Li}$ et al. 2007). B56 $\varepsilon$ also regulates the p53-dependent apoptotic pathway by controlling the stability of p53 protein (Jin et al. 2010).

Other findings implicate an important role for B56a-containing PP2A complexes in p53 degradation. One target of p53, cyclin G, recruits B56a into a quaternary complex with the E3 ubiquitin ligase, mouse double minute 2 (Mdm2) (Okamoto et al. 1996; Okamoto et al. 2002). The subsequent dephosphorylation and activation of Mdm2 leads to ubiquitination and degradation of p53 (Haupt et al. 1997), thus allowing the cell to proliferate. In this context, PP2A serves as a negative regulator.

\subsubsection{PP2A and c-Myc regulation}

PP2A also plays a prominent role in controlling the accumulation of the proto-oncoprotein, c-Myc (Yeh et al. 2004). Aberrant regulation of c-Myc has been linked to transformation in up to $70 \%$ of human tumors; therefore tight control of this protein is crucial for maintaining cellular homeostasis (Nesbit et al. 1999). c-Myc stability is regulated, in part, through phosphorylation at two residues, Ser62 and Thr58 (Sears et al. 2000). Whilst ERK-mediated phosphorylation at Ser62 stabilises c-Myc, specific B56 $\alpha$-containing PP2A complexes reverse these effects, leading to destabilisation and ubiquitin-mediated degradation (Arnold and 
Sears 2006). In addition, a novel PP2A-interacting protein, designated cancerous inhibitor of PP2A (CIP2A), was found to selectively target the catalytic activity of PP2A-B56a associated with c-Myc, and protect c-Myc from Ser62 dephosphorylation. Accordingly, depletion of CIP2A results in significantly increased PP2A activity measured from c-Myc immunoprecipitates and correlates with c-Myc destabilisation (Junttila et al. 2007).

Collectively, these results illustrate the dynamic interaction of the PP2A holoenzyme with signaling cascades involved in fundamental cellular processes such as proliferation, survival and development. The fact that PP2A is involved in both the negative and positive regulation of these pathways highlights the exquisite nature of PP2A modulation and underscores the importance of investigating specific complexes when determining PP2A function. Identification of critical subunits that are aberrantly regulated during transformation may ultimately lead to the development of novel treatments for cancer patients.

\subsection{PP2A as a tumor suppressor}

The fundamental evidence that implicated PP2A as a tumor suppressor was the discovery that okadaic acid, a tumor promoter (Fujiki and Suganuma 2009; Suganuma et al. 1988), potently inhibits the phosphatase activity of PP2A (Bialojan and Takai 1988; Haystead et al. 1989). In addition, the oncogenic polyomavirus middle and small tumor (ST) antigens, along with the simian virus 40 (SV40) ST antigen, transforms mammalian cells by inhibiting PP2A (Pallas et al. 1990). Transformation of the normal human fibroblast kidney epithelial cell line, HEK293, required several key genetic elements; human telomerase catalytic subunit, an oncogenic allele of H-Ras, and the SV40 large T (LT) and ST antigens (HEK-TER) (Hahn et al. 1999). Whilst expression of LT enables the cells to bypass senescence, complete tumor formation requires the addition of ST and thus inhibition of PP2A (Yu et al. 2001). Accordingly, ST mutants lacking the PP2A binding domain fail to induce tumorigenic transformation of HEK-TER cells (Hahn et al. 2002). Structural insights reveal that ST interacts with the PP2A-A subunit which overlaps B56 subunit binding site and results in its displacement from the core enzyme. Functionally, expression of ST activates Akt signaling in human cells in vitro (Rodriguez-Viciana et al. 2006; Yuan et al. 2002; Zhao et al. 2003). Taken together, these observations indicate that complete transformation of human cells requires the perturbation of PP2A, for example by ST.

A somewhat confusing aspect of PP2A function in cancer arises because PP2A plays important roles in promoting cell cycle progression and cell survival (Li et al. 2002; Lin et al. 1998; Mayer-Jaekel et al. 1993), which are functions usually associated with tumor initiation and progression rather than suppression. Therefore, cellular transformation will most likely occur through the disruption of PP2A holoenzymes that normally exert negative regulation on oncogenic pathways.

Whilst some contradiction exists as to the importance of PP2A scaffolding subunits in cancer development, several mutations have been identified in spontaneously arising human cancers. Notably, somatic alterations of the gene encoding A $\beta$ (PPP2R1B) have been detected in up to $8-15 \%$ of colon, $15 \%$ of lung and $13 \%$ of breast cancers (Calin et al. 2000; Takagi et al. 2000; Tamaki et al. 2004; Wang et al. 1998). Mutations of the more abundant Aa subunit have been observed, albeit at a lower frequency (Calin et al. 2000) and cancerassociated A subunit mutants exhibit differential defects in binding to the B and C subunits, which correlates with impaired PP2A activity (Chen et al. 2005; Ruediger et al. 2001a; 
Ruediger et al. 2001b; Sablina et al. 2007). Even in the absence of mutations, reduced protein expression of Aa has been found in 25 out of 58 brain tumors (Colella et al. 2001). Decreased levels of $A \beta$ have also been observed in 16 of 32 cancer cell lines derived from human lung, colon and breast cancer, as well as primary glioblastoma and B-CLL patient samples compared to normal tissue (Kalla et al. 2007; Suzuki and Takahashi 2003; Takagi et al. 2000; Zhou et al. 2003). Importantly, Ruediger et al., recently generated knock-in mice with cancer associated A $\alpha$ mutations, and A $\alpha$ knockouts, both of which exhibited increased incidence of lung cancer when treated with benzopyrene, thus supporting the role of PP2A as a tumor suppressor (Ruediger et al. 2011).

Pivotal studies using the HEK-TER transformation model demonstrated that suppression of $\mathrm{B} 56 \mathrm{\gamma}$, but not B55a, functionally mimicked the introduction of ST and resulted in partial tumorigenic transformation (Chen et al. 2004; Moreno et al. 2004). Moreover, depletion of B56y containing complexes leads to activation of the anti-apoptotic Akt pathway (Chen et al. 2005). These observations were the first to demonstrate that PP2A complexes containing B56y modulate the phosphorylation of substrates associated with transformation. Loss of B56y has been demonstrated in some human cancers. Decreased expression was identified in primary human melanoma samples compared to melanocytic nevi (Deichmann et al. 2001), and in human lung cancer cell lines where subsequent overexpression of B56Y reversed the tumorigenic phenotype (Chen et al. 2004). Reduced transcript levels of B56y have also been documented in patients with aggressive B-CLL compared to those with stable disease (Falt et al. 2005). A mutation in B56y has also been observed in lung cancer, and this was shown to disrupt the interaction of B56y with p53 (Shouse et al. 2010). In contrast, higher expression levels of B56 1 mRNA were reported in human melanoma cell lines compared to normal melanocytes (Francia et al. 1999).

Recently the HEK293T system was further utilised to systematically examine all PP2A regulatory subunits (Sablina et al. 2010). In addition to B56 $\gamma$, suppression of B56a, PR72/PR130, and PTPA (protein phosphatase 2A activator), replaced the expression of ST in transformation. Interestingly, the effects on signaling pathways differed depending on the regulatory subunit suppressed. Knockdown of B56Y and PTPA, but not B56a or PR72/PR130, led to enhanced Akt phosphorylation, while knockdown of B56a, PR72/PR130, and PTPA, but not B56y, resulted in increased c-Myc expression. Moreover, suppression of B56Y and PTPA led to increased $\beta$-catenin activity, whereas PR72/PR130 suppression decreased $\beta$-catenin activity (Sablina et al. 2010). Overexpression of CIP2A in the HEK-TER model can also replace ST in inducing transformation (Junttila et al. 2007), and increased CIP2A has been detected in myeloid leukemia patient samples (Wang and Li 2011), gastric and colon cancer samples (Khanna et al. 2009; Li et al. 2008; Soo Hoo et al. 2002)

\subsection{PP2A in myeloid leukemias}

An emerging body of evidence implicates PP2A as an important tumor suppressor in myeloid leukemias (Table 1). In particular, recent work from our laboratory and others has revealed a common theme in myeloid leukemias: inactivation of PP2A by leukemia associated tyrosine kinases (Fig. 3). Importantly, PP2A inhibition is essential for leukemias driven by these oncogenic tyrosine kinases, as re-activation of PP2A results in dephosphorylation, and thus deactivation, of the kinase and subsequent inhibition of leukemogenesis. Hence, re-activation of PP2A is an attractive strategy for leukemia therapy. 
A

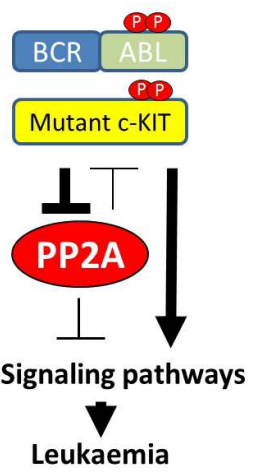

B

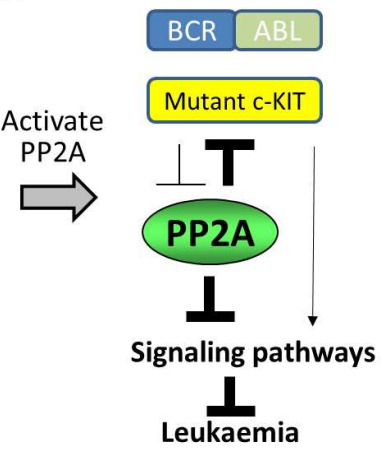

Fig. 3. Model of PP2A inhibition in myeloid leukemias. (A) PP2A activity is inhibited by $\mathrm{BCR} / \mathrm{ABL}$ and oncogenic mutant c-KIT, enabling the activation of signaling pathways leading to leukemogenesis. (B) Pharmacological activation of PP2A induces de-activation (dephosphorylation) of BCR/ABL and c-KIT, and inhibition of downstream signaling pathways, leading to inhibition of leukemogenesis.

\subsubsection{PP2A inhibition in CML}

Functional inactivation of PP2A by BCR/ABL is essential for the development of CML-BC and $\mathrm{Ph}^{+} \mathrm{ALL}$, and is thought to result from upregulation of the endogenous PP2A inhibitor SET $\left(\mathrm{I}_{2} \mathrm{PP} 2 \mathrm{~A}\right.$ or TAF-1 $\beta$ ) protein (Neviani et al. 2007; Neviani et al. 2005). Although its physiological function remains incompletely understood, abnormal expression of SET mRNA has been documented in solid tumors and haematological disorders (Carlson et al. 1998; Fornerod et al. 1995; Li et al. 1996). Expression of BCR/ABL in mouse myeloid precursor cells stimulates SET expression and correlates with a loss of PP2A activity (Neviani et al. 2005). Conversely, inhibition of BCR/ABL with imatinib treatment dramatically reduces SET expression, which results in the restoration of PP2A activity back to untransfected levels and results in the dephosphorylation of several substrates which are shared by BCR/ABL and PP2A (Neviani et al. 2005). These include STAT5, ERK1/2, Akt, BAD and JAK2 (Calabretta and Perrotti 2004; Janssens and Goris 2001). Importantly, molecular or pharmacological reactivation of PP2A resulted in growth suppression, enhanced apoptosis, restored differentiation, and decreased in vivo leukemogenesis of imatinib-sensitive and -resistant $\mathrm{BCR} / \mathrm{ABL}^{+}$cell lines and primary CML-BC cells. Furthermore, reactivation of PP2A, by overexpression of PP2AC or 1,9-dideoxyforskolin treatment (a cAMP-independent PP2A activator) (see section 6.5.1), reduced the activity and expression of $B C R / A B L$ in both imatinib-sensitive and -resistant $B C R / A B L$ cells, suggesting that $\mathrm{BCR} / \mathrm{ABL}$ itself is a target for PP2A activity. Indeed, reactivation of PP2A results in PP2AC association with $\mathrm{BCR} / \mathrm{ABL}$ via the SHP1 tyrosine phosphatase, BCR/ABL dephosphorylation, and proteasomal degradation (Neviani et al. 2005). These findings establish an important link between an oncogenic kinase and a tumor suppressing phosphatase, and indicate that pharmacologic enhancement of PP2A is a powerful therapeutic strategy for imatinib-resistant CML. Taken together, these results suggest that SET-dependent inhibition of PP2A is required for the transduction of aberrant mitogenic, survival and anti-differentiation signals that contribute to the development of CML from the chronic phase into blast crisis (Neviani et al. 2005). 


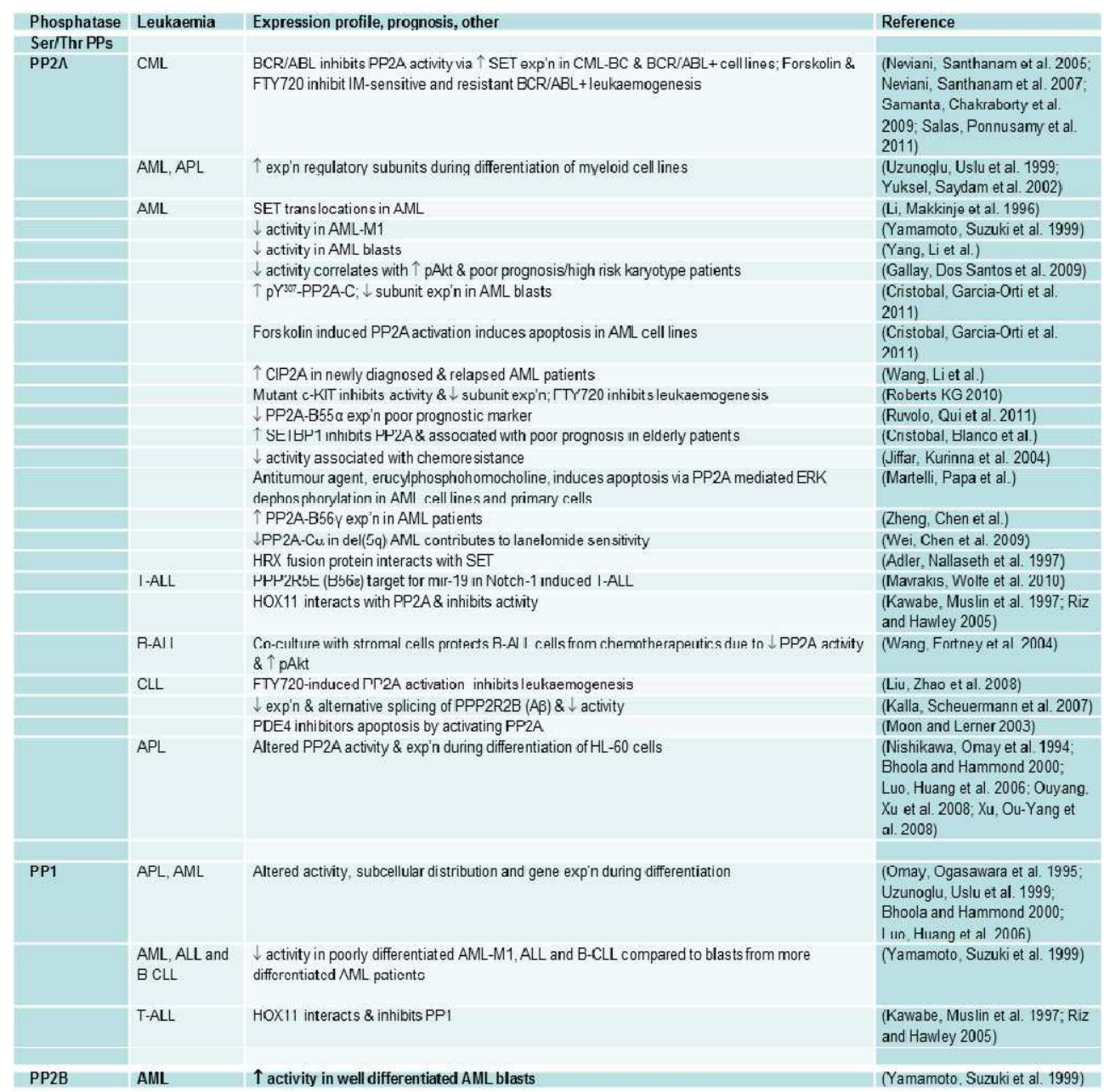

Table 1. Ser/Thr Phosphatases in Leukaemia

\subsubsection{PP2A inhibition in AML}

Oncogenic c-KIT signaling also requires inhibition of PP2A for leukemogenesis (Roberts et al. 2010). c-KIT is a receptor tyrosine kinase that activates similar proliferation, differentiation and survival signaling pathways as BCR/ABL, such as the PI3K, ERK and JAK/STAT pathways (Linnekin 1999). Gain-of-function c-KIT mutations occur in a range of malignancies, including AML, systemic mastocytosis, testicular seminoma, gastrointestinal stromal tumors (GIST) and melanomas, making c-KIT an excellent target for anti-cancer therapies (Kitamura and Hirota 2004; Masson and Ronnstrand 2009). These mutants induce hyperphosphorylation of c-KIT and constitutive activation of downstream signaling pathways (Masson and Ronnstrand 2009). Activating c- KIT mutations occur in up to $48 \%$ of core binding factor-AML (CBF-AML) patients, and are associated with increased relapse 
and reduced survival (Muller et al. 2008). While imatinib has shown remarkable success in treating c-KIT+ GIST patients (Demetri et al. 2002), the majority of c-KIT mutations expressed in AML patients are intrinsically resistant to imatinib, and as such, many CBFAML and systemic mastocytosis patients are unresponsive to imatinib therapy (Cairoli et al. 2005; Pardanani et al. 2003). Our laboratory has recently shown that myeloid precursor cells expressing oncogenic mutant c-KIT receptors display significantly reduced PP2A activity compared to c-KIT-negative or WT-c-KIT expressing cells (Roberts et al. 2010). Inhibition of PP2A by mutant c-KIT is associated with reduced protein expression of PP2A subunits, together with altered expression of the endogenous PP2A inhibitory protein SET. Overexpression of PP2A-A caused growth inhibition and apoptosis, suggesting that PP2A inhibition is functionally important in c-KIT mediated leukemogenesis. Importantly, reactivation of PP2A resulted in dephosphorylation (and hence deactivation) of the mutant c-KIT receptor itself, as well as inactivation of downstream signaling proteins required for cKIT induced leukemogenesis (e.g. Akt, ERK and STAT5) (Roberts et al. 2010). Furthermore, activation of PP2A by the pharmacological agent FTY720, inhibited leukemogenesis driven by mutant c-KIT (See section 6.5.2).

A number of recent studies further support a tumor suppressive role for PP2A in AML. Reduced expression of the PP2A-B55a subunit and increased Akt phophorylation in AML patient blasts was associated with shorter complete remission (Ruvolo et al. 2011). Hyperphosphorylation of PP2Ac, known to inhibit PP2A activity, has been observed in 78\% of AML patients. This was associated with enhanced expression of PP2A inhibitors SET, CIP2A, and/or SET binding protein 1 (SETBP1) (Cristobal et al. 2011). Reduced expression of PP2A-A and a number of PP2A regulatory subunits was also observed in a number of patients. Increased expression of SETBP1 was also shown to be induced by a novel translocation $\mathrm{t}(12 ; 18)(\mathrm{p} 13 ; \mathrm{q12})$ involving ETV6 in a patient with AML (Cristobal et al. 2010). SETBP1 overexpression protected SET from protease cleavage, leading to the formation of a SETBP1-SET-PP2A complex that results in PP2A inhibition, promoting proliferation of the leukemic cells. SETBP1 was further shown to be overexpressed in over $27 \%$ of AML patients and correlated with significantly shorter overall survival, in particular in patients over 60 years (Cristobal et al. 2010). Thus SETBP1 confers a negative prognostic impact and may be a predictive factor in any future clinical trials with PP2A activators. Increased expression of another PP2A inhibitory protein, CIP2A, has also been observed in diagnosis and relapse AML patients compared to patients in remission or healthy controls (Wang and Li 2011).

\subsection{Targeting PP2A for anti-leukemia therapy \\ 6.5.1 Forskolin}

Forskolin, a diterpene isolated from the roots of Coleus forskohlii, is primarily known to stimulate the adenylate cyclase system, which results in elevated levels of cyclic AMP (cAMP) and subsequent activation of protein kinase A (PKA) (Seamon and Daly 1981; Seamon et al. 1981). The anticancer properties of this compound were initially demonstrated through potent inhibition of growth and tumor colonisation of the highly metastatic BL6 melanoma cell line (Agarwal and Parks 1983). Further studies indicated its potential use against ALL (Gutzkow et al. 2002) and CML cell lines (Taetle and Li-en 1984). However, more recent findings demonstrate that forskolin also activates PP2A (Feschenko et al. 2002); a mechanism which contributes to induction of apoptosis in B-CLL, CML-BC and AML patient samples (Cristobal et al. 2011; Moon and Lerner 2003; Neviani et al. 2005). Neviani et 
al., was the first to highlight the therapeutic relevance of using PP2A-activators to specifically target leukemia cells (Neviani et al. 2005). Forskolin inhibited the in vivo leukemogenesis of imatinib sensitive and resistant BCR/ABL+ 32Dcl3 cells in mice, resulting in significantly prolonged survival. Furthermore, treatment with 1,9-dideoxyforskolin, which lacks adenylate cyclase activity, impaired the clonogenic potential of $\mathrm{BCR} / \mathrm{ABL}^{+} 32 \mathrm{Dcl} 3$ cells to a similar degree as forskolin, suggesting that the anti-leukaemic effects of forskolin and its derivative depends on the induction of PP2A activity rather than cAMP . Restoration of PP2A activity with forskolin was also found to inhibit Akt and ERK activity, block proliferation and induce caspase-dependant apoptosis in AML cell lines (Cristobal et al. 2011; Neviani et al. 2005). Furthermore, forskolin had an additive effect with common AML induction therapy drugs Idarubicin and Ara-c (Cristobal et al. 2011).

\subsubsection{FTY720}

FTY720 was first synthesised by structural modifications of myriocin (ISP-1), a fungal metabolite isolated from Isaria sinclairii culture broth (Fujita et al. 1994), and is structurally similar to sphingosine (Albert et al. 2005; Kiuchi et al. 2005). It is effectively phosphorylated in vivo by SphK2 to yield the biologically active FTY720-phosphate (FTY720-P) (Brinkmann et al. 2002; Zemann et al. 2006). Interaction of FTY720-P with one of the five known S1P receptors induces receptor internalisation and degradation (Graler and Goetzl 2004; Matloubian et al. 2004). The S1P signal is required for the migration of lymphocytes from secondary lymphoid tissues back into the efferent lymphatics and systemic circulation (Cyster 2005; Matloubian et al. 2004) and prolonged S1PR downregulation by FTY720-P inhibits the immune response by sequestering functional lymphocytes within secondary lymphoid organs (Brinkmann et al. 2002; Mandala et al. 2002). The use of FTY720 as an immunomodulator is currently being evaluated in Phase III trials for multiple sclerosis (Cohen et al. 2009; Takabe et al. 2008).

A more recent mechanism of action identified for FTY720 is its activation of purified PP2A trimers in vitro (Matsuoka et al. 2003) and as loss of PP2A phosphatase activity contributes to the pathophysiology of BCR/ABL-driven leukemias (Neviani et al. 2007) a logical prediction would be that restoration of PP2A levels reverses the leukaemic phenotype. Indeed, an extensive study has shown that pharmacological reactivation of PP2A with FTY720 inhibits the proliferation, enhances apoptosis, restores differentiation and impairs colony formation of imatinib-sensitive and -resistant BCR-ABL+ cell lines and CML-BC patient blasts (Neviani et al. 2007). Notably, FTY720 promotes BCR/ABL tyrosine dephosphorylation and proteolytic degradation, together with reduced phosphorylation of the PP2A targets Akt, ERK1/2 and STAT5 (Neviani et al. 2007). Co-treatment with okadaic acid or transduction of SV40 ST reverses the enhancement of PP2A activity and restores substrate phosphorylation, strongly indicating that FTY720 functions through a PP2A-dependent mechanism.

Importantly, the in vitro efficacy of FTY720 translated into an in vivo model markedly suppressing both imatinib-sensitive (WT) and -resistant (T315I) BCR/ $\mathrm{ABL}^{+}$leukemogenesis (Neviani et al. 2007). After 4 weeks of treatment, saline-treated mice contained a large number of undifferentiated myeloid cells within the peripheral circulation, representing an overt AML phenotype with extensive blast infiltration of distal organs. In contrast, FTY720treated mice displayed undetectable levels of $\mathrm{BCR} / \mathrm{ABL}^{+}$cells in the systemic circulation and secondary organs. Accordingly, these effects were sustained long term with $80 \%$ and $50 \%$ of $\mathrm{WT}$ and T315I BCR/ABL ${ }^{+}$FTY720-treated mice, respectively, still alive at 27 weeks 
and showing no signs of leukemia. In contrast, all saline-treated mice were sacrificed 5 weeks post-tumor cell injection (Neviani et al. 2007). No toxic side effects were observed with administration of FTY720, highlighting the safety and therapeutic relevance of utilising PP2A-activating drugs in leukemia patients.

FTY720 also activates PP2A in mutant c-KIT myeloid cells, leading to growth inhibition and induction of apoptosis in vitro (Roberts et al. 2010). Activation of PP2A is required for the anti-leukaemic effects, as PP2A inhibition with okadaic acid inhibits these effects. FTY720induced PP2A activity results in inhibition of c-KIT phosphorylation, and inactivation of downstream signaling proteins regulated by both c-KIT and PP2A. Importantly, FTY720 also inhibited the in vivo tumor growth of mutant c-KIT myeloid cells in a syngeneic mouse model (Roberts et al. 2010). Thus FTY720 may also be a useful therapeutic agent for CBFAML patients harbouring activating c-KIT mutations.

\section{Other serine/threonine phosphatases in myeloid leukemia}

\subsection{PP1}

PP1 activity has been found to alter according to AML blast differentiation. Yamamoto et al., found that AML patients with well differentiated leukemia had higher PP1 activity than patients with poorly differentiated AML-M1 (Yamamoto et al. 1999). AML blast PP1 activity also correlated with patient prognosis where individuals with significantly low PP1 activity had lower overall survival than those with high PP1 activity, with a median survival for each group of 8 and 27 months respectively (Nishikawa et al. 1994). Thus low PP1 activity may be a prognostic indicator of poor prognosis. The functional consequence of low PP1 activity in AML is not known, however PP1 was recently found to dephosphorylate Akt at T405, and PP1 overexpression induced Akt dephosphorylation, promoted cell survival and inhibited differentiation (Xiao et al. 2010). PP1 also promotes survival by negative regulation of p53 (Li et al. 2006), and is implicated in regulating Wnt/ $\beta$-catenin (Jiang et al. 2009), TGF- $\beta$ (Shi et al. 2004), and NF-kB (Li et al. 2008) signaling pathways. Luo et al., showed that arsenic sulfide, a therapy historically used for treating CML in China, inhibited proliferation and induced differentiation of a human APL HL-60 cell line down a monocytic pathway. This correlated with increasing PP1 and PP2A activity, and co-treatment with a concentration of OA that inhibits both phosphatases suppressed the arsenic sulfide induced differentiation (Luo et al. 2006). Furthermore, while the mechanism was unknown at the time, other studies had previously shown similar effect in an APL NB4 cell model (Bai and Huang 1998; Lu and Wang 2002) and in chronic myeloid leukemia K562 cells (Yin et al. 2004). These studies suggest that PP1 plays a role in the growth inhibition and differentiation of AML, and may also provide a useful prognostic tool and/or therapy target.

\subsection{PP2B}

PP2B (calcineurin) is probably best known for its role in immunity where it is activated upon $\mathrm{T}$ cell receptor stimulation. Indeed, calcineurin is a well established target of prophylactic agents used in transplantation, such as Cyclosporin A and FK506, where calcineurin inhibition suppresses IL-2 production. Calcineurin was recently implicated as an important oncogene in lymphoid leukemias (Medyouf et al. 2007; Medyouf and Ghysdael 2008; Muller and Rao 2007). Sustained calcineurin activity was observed in human B- and Tcell lymphomas and in a range of mouse models of lymphoid malignancies. Moreover, 
expression of constitutively active mutant calcineurin favored leukemia progression, while treatment with Cyclosporin A or FK506 induced apoptosis of leukemic cells and rapid tumor clearance, and significantly improved mouse survival (Medyouf et al. 2007). Thus inhibiting calcineurin is a potential therapeutic strategy for lymphoid leukemias. In contrast, a specific role for calcineurin in myeloid leukemias has not been reported, however one study investigating its activity in AML patients of different FAB subtype found that calcineurin activity is relatively low in leukemic blasts arresting at the stage of early pluripotent stem cells, and increases during the course of myelomonocytic commitment and maturation (Yamamoto et al. 1999).

\subsection{PP2C}

Like PP2B, little information exists regarding the role of PP2C in myeloid leukemia. One study revealed it had low expression in AML patient blood cells and its activity and expression were relatively constant in various leukemic cell types from AML, ALL, and CLL patients (Yamamoto et al. 1999), suggesting it may not play a remarkable role in leukemogenesis.

\section{Conclusions}

There is no doubt that PP2A acts as a tumor suppressor in myeloid leukemias, and targeting its re-activation, either directly or via inhibition of an endogenous inhibitory protein such as SET, is a promising therapeutic strategy. Whether the pre-clinical promise will translate to improved survival of myeloid leukemia patients is currently unknown, but clinical trials of PP2A activators are eagerly awaited. Emerging studies indicate that other phosphatases may also play important roles in myeloid leukemias, and future studies aimed at deciphering the molecular mechanisms regulating these phosphatases and their downstream targets is sure to identify further targets for novel therapies.

\section{Acknowledgements}

This work was supported by grants from the Cancer Council NSW, the Anthony Rothe Memorial Foundation, and the Hunter Medical Research Institute (HMRI). AMS was supported by an Australian Postgraduate Award (APA) and an Arrow Bone Marrow Trust scholarship, KGR by an APA and Cancer Institute NSW scholarship, and NMV by a National Health and Medical Research Council (NHMRC) Peter Doherty Fellowship.

\section{References}

Abraham, D., K. Podar, et al. (2000). "Raf-1-associated protein phosphatase 2A as a positive regulator of kinase activation."J Biol Chem, 27529: 22300-22304 0021-9258 (Print).

Adams, D. G., R. L. Coffee, Jr., et al. (2005). "Positive regulation of Raf1-MEK1/2-ERK1/2 signaling by protein serine/threonine phosphatase 2A holoenzymes."J Biol Chem, 28052: 42644-42654 0021-9258 (Print).

Adler, H. T., F. S. Nallaseth, et al. (1997). "HRX leukemic fusion proteins form a heterocomplex with the leukemia-associated protein SET and protein phosphatase 2A."J Biol Chem, 27245: 28407-28414 0021-9258 (Print) 
Agarwal, K. C. and R. E. Parks, Jr. (1983). "Forskolin: a potential antimetastatic agent."Int J Cancer, 326: 801-804 0020-7136 (Print).

Albert, R., K. Hinterding, et al. (2005). "Novel immunomodulator FTY720 is phosphorylated in rats and humans to form a single stereoisomer. Identification, chemical proof, and biological characterization of the biologically active species and its enantiomer."J Med Chem, 4816: 5373-5377 0022-2623 (Print).

Alessi, D. R., N. Gomez, et al. (1995). "Inactivation of p42 MAP kinase by protein phosphatase $2 \mathrm{~A}$ and a protein tyrosine phosphatase, but not CL100, in various cell lines."Curr Biol, 53: 283-295.

Alonso, A., J. Sasin, et al. (2004). "Protein tyrosine phosphatases in the human genome."Cell, 1176: 699-711 0092-8674 (Print).

Andrabi, S., O. V. Gjoerup, et al. (2007). "Protein phosphatase 2A regulates life and death decisions via Akt in a context-dependent manner."Proc Natl Acad Sci U S A, 10448: 19011-19016.

Arino, J., C. W. Woon, et al. (1988). "Human liver phosphatase 2A: cDNA and amino acid sequence of two catalytic subunit isotypes."Proc Natl Acad Sci U S A, 8512: 4252$42560027-8424$ (Print).

Arnold, H. K. and R. C. Sears (2006). "Protein phosphatase 2A regulatory subunit B56alpha associates with c-myc and negatively regulates c-myc accumulation."Mol Cell Biol, 267: 2832-2844.

Bai, Y. and S. Huang (1998). "[Studies on red orpiment induction of NB4 and HL-60 cell apoptosis]."Zhonghua Xue Ye Xue Za Zhi, 199: 477-480 0253-2727 (Print).

Bajpai, R., K. Makhijani, et al. (2004). "Drosophila Twins regulates Armadillo levels in response to Wg/Wnt signal."Development, 1315: 1007-1016 0950-1991 (Print).

Barford, D., A. K. Das, et al. (1998). "The structure and mechanism of protein phosphatases: insights into catalysis and regulation."Annu Rev Biophys Biomol Struct, 27: 133-164 1056-8700 (Print).

Begley, M. J. and J. E. Dixon (2005). "The structure and regulation of myotubularin phosphatases."Curr Opin Struct Biol, 156: 614-620 0959-440X (Print).

Bentires-Alj, M., J. G. Paez, et al. (2004). "Activating mutations of the noonan syndromeassociated SHP2/PTPN11 gene in human solid tumors and adult acute myelogenous leukemia."Cancer Res, 6424: 8816-8820 0008-5472 (Print).

Bhoola, R. and K. Hammond (2000). "Modulation of the rhythmic patterns of expression of phosphoprotein phosphatases in human leukaemia cells."Cell Biol Int, 248: 539-547 1065-6995 (Print).

Bialojan, C. and A. Takai (1988). "Inhibitory effect of a marine-sponge toxin, okadaic acid, on protein phosphatases. Specificity and kinetics."Biochem J, 2561: 283-290.

Borgatti, P., A. M. Martelli, et al. (2003). "Threonine 308 phosphorylated form of Akt translocates to the nucleus of PC12 cells under nerve growth factor stimulation and associates with the nuclear matrix protein nucleolin."J Cell Physiol, 1961: 79-88 00219541 (Print).

Brinkmann, V., M. D. Davis, et al. (2002). "The immune modulator FTY720 targets sphingosine 1-phosphate receptors."J Biol Chem, 27724: 21453-21457 0021-9258 (Print).

Bruecher-Encke, B., J. D. Griffin, et al. (2001). "Role of the tyrosine phosphatase SHP-1 in K562 cell differentiation."Leukemia, 159: 1424-1432 0887-6924 (Print). 
Cairoli, R., A. Beghini, et al. (2005). "Imatinib mesylate in the treatment of Core Binding Factor leukemias with KIT mutations. A report of three cases."Leuk Res, 294: 397400 .

Calabretta, B. and D. Perrotti (2004). "The biology of CML blast crisis."Blood, 10311: 40104022.

Calin, G. A., M. G. di Iasio, et al. (2000). "Low frequency of alterations of the alpha (PPP2R1A) and beta (PPP2R1B) isoforms of the subunit A of the serine-threonine phosphatase 2A in human neoplasms."Oncogene, 199: 1191-1195 0950-9232 (Print).

Carlson, S. G., E. Eng, et al. (1998). "Expression of SET, an inhibitor of protein phosphatase 2A, in renal development and Wilms' tumor."J Am Soc Nephrol, 910: 1873-1880.

Chen, W., J. D. Arroyo, et al. (2005). "Cancer-associated PP2A Aalpha subunits induce functional haploinsufficiency and tumorigenicity."Cancer Res, 6518: 8183-8192 00085472 (Print).

Chen, W., R. Possemato, et al. (2004). "Identification of specific PP2A complexes involved in human cell transformation."Cancer Cell, 52: 127-136.

Chim, C. S., T. K. Fung, et al. (2004). "SOCS1 and SHP1 hypermethylation in multiple myeloma: implications for epigenetic activation of the Jak/STAT pathway."Blood, 10312: 4630-4635 0006-4971 (Print).

Cohen, J., J. Pelletier, et al. (2009). Oral Fingolimod (FTY720) Versus Interferon Beta-1a in RelapsingRemitting Multiple Sclerosis: Results from a Phase III Study (TRANSFORMS). Proceedings of American Academy of Neurology, Seattle, April 25 May 2

Cohen, P. (1989). "The structure and regulation of protein phosphatases."Annu Rev Biochem, 58: 453-508 0066-4154 (Print).

Cohen, P. (2002). "Protein kinases--the major drug targets of the twenty-first century?"Nat Rev Drug Discov, 14: 309-315 1474-1776 (Print).

Colella, S., H. Ohgaki, et al. (2001). "Reduced expression of the Aalpha subunit of protein phosphatase 2A in human gliomas in the absence of mutations in the Aalpha and Abeta subunit genes."Int J Cancer, 936: 798-804.

Creyghton, M. P., G. Roel, et al. (2005). "PR72, a novel regulator of Wnt signaling required for Naked cuticle function."Genes Dev, 193: 376-386.

Creyghton, M. P., G. Roel, et al. (2006). "PR130 is a modulator of the Wnt-signaling cascade that counters repression of the antagonist Naked cuticle."Proc Natl Acad Sci U S A, 10314: 5397-5402.

Cristobal, I., F. J. Blanco, et al. (2010). "SETBP1 overexpression is a novel leukemogenic mechanism that predicts adverse outcome in elderly patients with acute myeloid leukemia."Blood, 1153: 615-625 1528-0020 (Electronic).

Cristobal, I., L. Garcia-Orti, et al. (2011). "PP2A impaired activity is a common event in acute myeloid leukemia and its activation by forskolin has a potent anti-leukemic effect."Leukemia, 254: 606-614 1476-5551 (Electronic).

Cyster, J. G. (2005). "Chemokines, sphingosine-1-phosphate, and cell migration in secondary lymphoid organs."Annu Rev Immunol, 23: 127-159 0732-0582 (Print).

Deichmann, M., M. Polychronidis, et al. (2001). "The protein phosphatase 2A subunit Bgamma gene is identified to be differentially expressed in malignant melanomas by subtractive suppression hybridization."Melanoma Res, 116: 577-585. 
Demetri, G. D., M. von Mehren, et al. (2002). "Efficacy and safety of imatinib mesylate in advanced gastrointestinal stromal tumors."N Engl J Med, 3477: 472-480.

Dohoney, K. M., C. Guillerm, et al. (2004). "Phosphorylation of p53 at serine 37 is important for transcriptional activity and regulation in response to DNA damage."Oncogene, 231: 49-57 0950-9232 (Print).

Dougherty, M. K., J. Muller, et al. (2005). "Regulation of Raf-1 by direct feedback phosphorylation."Mol Cell, 172: 215-224.

Eichhorn, P. J., M. P. Creyghton, et al. (2009). "Protein phosphatase 2A regulatory subunits and cancer."Biochim Biophys Acta, 17951: 1-15 0006-3002 (Print).

Falt, S., M. Merup, et al. (2005). "Identification of progression markers in B-CLL by gene expression profiling."Exp Hematol, 338: 883-893 0301-472X (Print).

Feschenko, M. S., E. Stevenson, et al. (2002). "A novel cAMP-stimulated pathway in protein phosphatase 2A activation."J Pharmacol Exp Ther, 3021: 111-118 0022-3565 (Print).

Fornerod, M., J. Boer, et al. (1995). "Relocation of the carboxyterminal part of CAN from the nuclear envelope to the nucleus as a result of leukemia-specific chromosome rearrangements."Oncogene, 109: 1739-1748.

Foulkes, J. G. and P. Cohen (1980). "The regulation of glycogen metabolism. Purification and properties of protein phosphatase inhibitor-2 from rabbit skeletal muscle."Eur J Biochem, 1051: 195-203 0014-2956 (Print).

Francia, G., R. Poulsom, et al. (1999). "Identification by differential display of a protein phosphatase-2A regulatory subunit preferentially expressed in malignant melanoma cells."Int J Cancer, 825: 709-713.

Fujiki, H. and M. Suganuma (2009). "Carcinogenic aspects of protein phosphatase 1 and 2A inhibitors."Prog Mol Subcell Biol, 46: 221-254.

Fujita, T., K. Inoue, et al. (1994). "Fungal metabolites. Part 11. A potent immunosuppressive activity found in Isaria sinclairii metabolite."J Antibiot (Tokyo), 472: 208-215 00218820 (Print).

Gallay, N., C. Dos Santos, et al. (2009). "The level of AKT phosphorylation on threonine 308 but not on serine 473 is associated with high-risk cytogenetics and predicts poor overall survival in acute myeloid leukaemia."Leukemia, 236: 1029-1038 1476-5551 (Electronic).

Gallego, M. and D. M. Virshup (2005). "Protein serine/threonine phosphatases: life, death, and sleeping."Curr Opin Cell Biol, 172: 197-202 0955-0674 (Print).

Gotz, J., A. Probst, et al. (2000). "Distinct role of protein phosphatase 2A subunit Calpha in the regulation of E-cadherin and beta-catenin during development."Mech Dev, 9312: 83-93.

Graler, M. H. and E. J. Goetzl (2004). "The immunosuppressant FTY720 down-regulates sphingosine 1-phosphate G-protein-coupled receptors."Faseb J, 183: 551-553 15306860 (Electronic).

Gutzkow, K. B., S. Naderi, et al. (2002). "Forskolin-mediated G1 arrest in acute lymphoblastic leukaemia cells: phosphorylated pRB sequesters E2Fs."J Cell Sci, 115Pt 5: 1073-1082 0021-9533 (Print).

Hahn, W. C., C. M. Counter, et al. (1999). "Creation of human tumour cells with defined genetic elements."Nature, 4006743: 464-468 0028-0836 (Print).

Hahn, W. C., S. K. Dessain, et al. (2002). "Enumeration of the simian virus 40 early region elements necessary for human cell transformation."Mol Cell Biol, 227: 2111-2123. 
Haupt, Y., R. Maya, et al. (1997). "Mdm2 promotes the rapid degradation of p53."Nature, 3876630: 296-299 0028-0836 (Print).

Haystead, T. A., A. T. Sim, et al. (1989). "Effects of the tumour promoter okadaic acid on intracellular protein phosphorylation and metabolism."Nature, 3376202: 78-81 00280836 (Print).

Hemmings, B. A., C. Adams-Pearson, et al. (1990). "alpha- and beta-forms of the 65-kDa subunit of protein phosphatase 2A have a similar 39 amino acid repeating structure."Biochemistry, 2913: 3166-3173 0006-2960 (Print).

Hendrix, P., R. E. Mayer-Jackel, et al. (1993). "Structure and expression of a 72-kDa regulatory subunit of protein phosphatase 2A. Evidence for different size forms produced by alternative splicing."J Biol Chem, 26820: 15267-15276 0021-9258 (Print).

Heriche, J. K., F. Lebrin, et al. (1997). "Regulation of protein phosphatase 2A by direct interaction with casein kinase 2alpha."Science, 2765314: 952-955.

Hsu, W., L. Zeng, et al. (1999). "Identification of a domain of Axin that binds to the serine/threonine protein phosphatase 2A and a self-binding domain."J Biol Chem, 2746: 3439-3445.

Ingebritsen, T. S. and P. Cohen (1983a). "Protein phosphatases: properties and role in cellular regulation."Science, 2214608: 331-338 0036-8075 (Print).

Ingebritsen, T. S. and P. Cohen (1983b). "The protein phosphatases involved in cellular regulation. 1. Classification and substrate specificities."Eur J Biochem, 1322: 255-261 0014-2956 (Print).

Ivaska, J., L. Nissinen, et al. (2002). "Integrin alpha 2 beta 1 promotes activation of protein phosphatase 2A and dephosphorylation of Akt and glycogen synthase kinase 3 beta."Mol Cell Biol, 225: 1352-1359 0270-7306 (Print).

Janssens, V. and J. Goris (2001). "Protein phosphatase 2A: a highly regulated family of serine/threonine phosphatases implicated in cell growth and signalling."Biochem J, 353Pt 3: 417-439 0264-6021 (Print).

Janssens, V., S. Longin, et al. (2008). "PP2A holoenzyme assembly: in cauda venenum (the sting is in the tail)."Trends Biochem Sci, 333: 113-121 0968-0004 (Print).

Jaumot, M. and J. F. Hancock (2001). "Protein phosphatases 1 and 2A promote Raf-1 activation by regulating 14-3-3 interactions."Oncogene, 2030: 3949-3958 0950-9232 (Print).

Jiang, Y., W. Luo, et al. (2009). "Dab2 stabilizes Axin and attenuates Wnt/beta-catenin signaling by preventing protein phosphatase 1 (PP1)-Axin interactions."Oncogene, 2833: 2999-3007 1476-5594 (Electronic).

Jiang, Z. X. and Z. Y. Zhang (2008). "Targeting PTPs with small molecule inhibitors in cancer treatment."Cancer Metastasis Rev, 272: 263-272 0167-7659 (Print).

Jiffar, T., S. Kurinna, et al. (2004). "PKC alpha mediates chemoresistance in acute lymphoblastic leukemia through effects on $\mathrm{Bcl} 2$ phosphorylation."Leukemia, 183: 505-512 0887-6924 (Print).

Jin, Z., L. Wallace, et al. (2010). "PP2A:B56\{epsilon\}, a substrate of caspase-3, regulates p53dependent and p53-independent apoptosis during development."The Journal of biological chemistry, 28545: 34493-34502 1083-351X (Electronic).

Johan, M. F., D. T. Bowen, et al. (2005). "Aberrant methylation of the negative regulators RASSFIA, SHP-1 and SOCS-1 in myelodysplastic syndromes and acute myeloid leukaemia."Br J Haematol, 1291: 60-65 0007-1048 (Print). 
Julien, S. G., N. Dube, et al. (2011). "Inside the human cancer tyrosine phosphatome."Nat Rev Cancer, 111: 35-49 1474-1768 (Electronic)

Junttila, M. R., P. Puustinen, et al. (2007). "CIP2A inhibits PP2A in human malignancies."Cell, 1301: 51-62.

Kalla, C., M. O. Scheuermann, et al. (2007). "Analysis of 11q22-q23 deletion target genes in Bcell chronic lymphocytic leukaemia: evidence for a pathogenic role of NPAT, CUL5, and PPP2R1B."Eur J Cancer, 438: 1328-1335 0959-8049 (Print).

Kawabe, T., A. J. Muslin, et al. (1997). "HOX11 interacts with protein phosphatases PP2A and PP1 and disrupts a G2/M cell-cycle checkpoint."Nature, 3856615: 454-458 00280836 (Print).

Khanna, A., C. Bockelman, et al. (2009). "MYC-Dependent Regulation and Prognostic Role of CIP2A in Gastric Cancer."J. Natl. Cancer Inst., 10111: 793-805.

Kitamura, Y. and S. Hirota (2004). "Kit as a human oncogenic tyrosine kinase."Cell Mol Life Sci, 6123: 2924-2931.

Kiuchi, M., K. Adachi, et al. (2005). "Asymmetric synthesis and biological evaluation of the enantiomeric isomers of the immunosuppressive FTY720-phosphate."Bioorg Med Chem, 132: 425-432 0968-0896 (Print).

Kubicek, M., M. Pacher, et al. (2002). "Dephosphorylation of Ser-259 regulates Raf-1 membrane association."J Biol Chem, 27710: 7913-7919 0021-9258 (Print).

Kuo, Y. C., K. Y. Huang, et al. (2008). "Regulation of phosphorylation of Thr-308 of Akt, cell proliferation, and survival by the B55alpha regulatory subunit targeting of the protein phosphatase 2A holoenzyme to Akt."J Biol Chem, 2834: 1882-1892.

Letourneux, C., G. Rocher, et al. (2006). "B56-containing PP2A dephosphorylate ERK and their activity is controlled by the early gene IEX-1 and ERK."Embo J, 254: 727-738.

Li, D. W., J. P. Liu, et al. (2006). "Protein serine/threonine phosphatase-1 dephosphorylates p53 at Ser-15 and Ser-37 to modulate its transcriptional and apoptotic activities."Oncogene, 2521: 3006-3022 0950-9232 (Print).

Li, H. H., X. Cai, et al. (2007). "A specific PP2A regulatory subunit, B56gamma, mediates DNA damage-induced dephosphorylation of p53 at Thr55."Embo J, 262: 402-411.

Li, H. Y., H. Liu, et al. (2008). "Deactivation of the kinase IKK by CUEDC2 through recruitment of the phosphatase PP1."Nat Immunol, 95: 533-541 1529-2916 (Electronic).

Li, M., A. Makkinje, et al. (1996). "The myeloid leukemia-associated protein SET is a potent inhibitor of protein phosphatase 2A."J Biol Chem, 27119: 11059-11062 0021-9258 (Print).

Li, W., Z. Ge, et al. (2008). "CIP2A Is Overexpressed in Gastric Cancer and Its Depletion Leads to Impaired Clonogenicity, Senescence, or Differentiation of Tumor Cells."Clin Cancer Res, 1412: 3722-3728.

Li, X., A. Scuderi, et al. (2002). "B56-associated protein phosphatase 2A is required for survival and protects from apoptosis in Drosophila melanogaster."Mol Cell Biol, 2211: 3674-3684.

Li, X., H. J. Yost, et al. (2001). "Protein phosphatase 2A and its B56 regulatory subunit inhibit Wnt signaling in Xenopus."Embo J, 2015: 4122-4131.

Lin, X. H., J. Walter, et al. (1998). "Protein phosphatase 2A is required for the initiation of chromosomal DNA replication."Proc Natl Acad Sci U S A, 9525: 14693-14698 00278424 (Print). 
Linnekin, D. (1999). "Early signaling pathways activated by c-Kit in hematopoietic cells."Int J Biochem Cell Biol, 3110: 1053-1074.

Liu, Q., X. Zhao, et al. (2008). "FTY720 demonstrates promising preclinical activity for chronic lymphocytic leukemia and lymphoblastic leukemia/lymphoma."Blood, 111.

Lopez-Ruiz, P., J. Rodriguez-Ubreva, et al. (2011). "SHP-1 in cell-cycle regulation."Anticancer Agents Med Chem, 111: 89-98 1875-5992 (Electronic).

Lorenz, U., A. D. Bergemann, et al. (1996). "Genetic analysis reveals cell type-specific regulation of receptor tyrosine kinase c-Kit by the protein tyrosine phosphatase SHP1."J Exp Med, 1843: 1111-1126 0022-1007 (Print).

Lu, D. P. and Q. Wang (2002). "Current study of APL treatment in China."Int J Hematol, 76 Suppl 1: 316-318 0925-5710 (Print).

Luo, L. Y., J. Huang, et al. (2006). "Induction of human promyelocytic leukemia HL-60 cell differentiation into monocytes by arsenic sulphide: involvement of serine/threonine protein phosphatases."Leuk Res, 3011: 1399-1405 0145-2126 (Print).

Mandala, S., R. Hajdu, et al. (2002). "Alteration of lymphocyte trafficking by sphingosine-1phosphate receptor agonists."Science, 2965566: 346-349 1095-9203 (Electronic).

Manning, G., D. B. Whyte, et al. (2002). "The protein kinase complement of the human genome."Science, 2985600: 1912-1934 1095-9203 (Electronic).

Martelli, A. M., V. Papa, et al. (2010). "Erucylphosphohomocholine, the first intravenously applicable alkylphosphocholine, is cytotoxic to acute myelogenous leukemia cells through JNK- and PP2A-dependent mechanisms."Leukemia, 244: 687-698 1476-5551 (Electronic).

Masson, K. and L. Ronnstrand (2009). "Oncogenic signaling from the hematopoietic growth factor receptors c-Kit and Flt3."Cell Signal, 2112: 1717-1726.

Matloubian, M., C. G. Lo, et al. (2004). "Lymphocyte egress from thymus and peripheral lymphoid organs is dependent on S1P receptor 1."Nature, 4276972: 355-360.

Matsuoka, Y., Y. Nagahara, et al. (2003). "A novel immunosuppressive agent FTY720 induced Akt dephosphorylation in leukemia cells."Br J Pharmacol, 1387: 1303-1312 0007-1188 (Print).

Mavrakis, K. J., A. L. Wolfe, et al. (2010). "Genome-wide RNA-mediated interference screen identifies miR-19 targets in Notch-induced T-cell acute lymphoblastic leukaemia."Nat Cell Biol, 124: 372-379 1476-4679 (Electronic).

Mayer-Jaekel, R. E., H. Ohkura, et al. (1993). "The 55 kd regulatory subunit of Drosophila protein phosphatase 2A is required for anaphase."Cell, 724: 621-633 0092-8674 (Print).

Mayer, R. E., P. Hendrix, et al. (1991). "Structure of the 55-kDa regulatory subunit of protein phosphatase 2A: evidence for a neuronal-specific isoform."Biochemistry, 3015: 35893597 0006-2960 (Print).

McCright, B., A. M. Rivers, et al. (1996). "The B56 family of protein phosphatase 2A (PP2A) regulatory subunits encodes differentiation-induced phosphoproteins that target PP2A to both nucleus and cytoplasm."J Biol Chem, 27136: 22081-22089 0021-9258 (Print).

McCright, B. and D. M. Virshup (1995). "Identification of a new family of protein phosphatase 2A regulatory subunits."J Biol Chem, 27044: 26123-26128 0021-9258 (Print). 
Medyouf, H., H. Alcalde, et al. (2007). "Targeting calcineurin activation as a therapeutic strategy for T-cell acute lymphoblastic leukemia."Nat Med, 136: 736-741 1078-8956 (Print).

Medyouf, H. and J. Ghysdael (2008). "The calcineurin/NFAT signaling pathway: a novel therapeutic target in leukemia and solid tumors."Cell Cycle, 73: 297-303 1551-4005 (Electronic).

Moon, E. Y. and A. Lerner (2003). "PDE4 inhibitors activate a mitochondrial apoptotic pathway in chronic lymphocytic leukemia cells that is regulated by protein phosphatase 2A."Blood, 10110: 4122-4130 0006-4971 (Print).

Moorhead, G. B., L. Trinkle-Mulcahy, et al. (2007). "Emerging roles of nuclear protein phosphatases."Nat Rev Mol Cell Biol, 83: 234-244 1471-0072 (Print).

Moreno, C. S., S. Ramachandran, et al. (2004). "Signaling and transcriptional changes critical for transformation of human cells by simian virus 40 small tumor antigen or protein phosphatase 2A B56gamma knockdown."Cancer Res, 6419: 6978-6988.

Muller, A. M., J. Duque, et al. (2008). "Complementing mutations in core binding factor leukemias: from mouse models to clinical applications."Oncogene, 2744: 5759-5773.

Muller, M. R. and A. Rao (2007). "Linking calcineurin activity to leukemogenesis."Nat Med, 136: 669-671 1078-8956 (Print).

Neel, B. G., H. Gu, et al. (2003). "The 'Shp'ing news: SH2 domain-containing tyrosine phosphatases in cell signaling."Trends Biochem Sci, 286: 284-293 0968-0004 (Print).

Nesbit, C. E., J. M. Tersak, et al. (1999). "MYC oncogenes and human neoplastic disease."Oncogene, 1819: 3004-3016.

Neviani, P., R. Santhanam, et al. (2007). "FTY720, a new alternative for treating blast crisis chronic myelogenous leukemia and Philadelphia chromosome-positive acute lymphocytic leukemia."J Clin Invest, 1179: 2408-2421 0021-9738 (Print).

Neviani, P., R. Santhanam, et al. (2005). "The tumor suppressor PP2A is functionally inactivated in blast crisis CML through the inhibitory activity of the BCR/ABLregulated SET protein."Cancer Cell, 85: 355-368 1535-6108 (Print).

Nimmo, G. A. and P. Cohen (1978). "The regulation of glycogen metabolism. Phosphorylation of inhibitor-1 from rabbit skeletal muscle, and its interaction with protein phosphatases-III and -II."Eur J Biochem, 872: 353-365 0014-2956 (Print).

Nishikawa, M., S. B. Omay, et al. (1994). "Expression of the catalytic and regulatory subunits of protein phosphatase type $2 \mathrm{~A}$ may be differentially modulated during retinoic acid-induced granulocytic differentiation of HL-60 cells."Cancer Res, 5418: 4879-4884 0008-5472 (Print).

Oka, T., M. Ouchida, et al. (2002). "Gene silencing of the tyrosine phosphatase SHP1 gene by aberrant methylation in leukemias/lymphomas."Cancer Res, 6222: 6390-6394 00085472 (Print).

Okamoto, K., C. Kamibayashi, et al. (1996). "p53-dependent association between cyclin G and the B' subunit of protein phosphatase 2A."Mol Cell Biol, 1611: 6593-6602.

Okamoto, K., H. Li, et al. (2002). "Cyclin G recruits PP2A to dephosphorylate Mdm2."Mol Cell, 94: 761-771.

Olsen, J. V., B. Blagoev, et al. (2006). "Global, in vivo, and site-specific phosphorylation dynamics in signaling networks."Cell, 1273: 635-648 0092-8674 (Print). 
Omay, S. B., H. Ogasawara, et al. (1995). "Translocation of protein phosphatase 1 catalytic subunits during 1,25-dihydroxyvitamin D3-induced monocytic differentiation of HL-60 cells."Cancer Res, 554: 774-780 0008-5472 (Print).

Ory, S., M. Zhou, et al. (2003). "Protein phosphatase 2A positively regulates Ras signaling by dephosphorylating KSR1 and Raf-1 on critical 14-3-3 binding sites."Curr Biol, 1316: 1356-1364.

Ouyang, J., X. H. Xu, et al. (2008). "Involvement of protein phosphatase 2A in arsenic trioxide-induced differentiation and apoptosis of NB4 cells."Methods Find Exp Clin Pharmacol, 306: 411-419 0379-0355 (Print).

Pallas, D. C., L. K. Shahrik, et al. (1990). "Polyoma small and middle T antigens and SV40 small $\mathrm{t}$ antigen form stable complexes with protein phosphatase 2A."Cell, 601: 167176.

Pardanani, A., M. Elliott, et al. (2003). "Imatinib for systemic mast-cell disease."Lancet, 3629383: 535-536.

Ratcliffe, M. J., K. Itoh, et al. (2000). "A positive role for the PP2A catalytic subunit in Wnt signal transduction."J Biol Chem, 27546: 35680-35683.

Resjo, S., O. Goransson, et al. (2002). "Protein phosphatase 2A is the main phosphatase involved in the regulation of protein kinase B in rat adipocytes."Cell Signal, 143: 231-238 0898-6568 (Print).

Riz, I. and R. G. Hawley (2005). "G1/S transcriptional networks modulated by the HOX11/TLX1 oncogene of T-cell acute lymphoblastic leukemia."Oncogene, 2436: 5561-5575 0950-9232 (Print).

Roberts, K. G., A. M. Smith, et al. (2010). "Essential requirement for PP2A inhibition by the oncogenic receptor c-KIT suggests PP2A reactivation as a strategy to treat c-KIT+ cancers."Cancer Res, 7013: 9.

Rodriguez-Viciana, P., C. Collins, et al. (2006). "Polyoma and SV40 proteins differentially regulate PP2A to activate distinct cellular signaling pathways involved in growth control."Proc Natl Acad Sci U S A, 10351: 19290-19295.

Ruediger, R., H. T. Pham, et al. (2001a). "Alterations in protein phosphatase 2A subunit interaction in human carcinomas of the lung and colon with mutations in the A beta subunit gene."Oncogene, 2015: 1892-1899.

Ruediger, R., H. T. Pham, et al. (2001b). "Disruption of protein phosphatase 2A subunit interaction in human cancers with mutations in the A alpha subunit gene."Oncogene, 201: 10-15.

Ruediger, R., J. Ruiz, et al. (2011). "Human Cancer-Associated Mutations in A\{alpha\} Subunit of Protein Phosphatase 2A Increase Lung Cancer Incidence in A\{alpha\} Knock-in and Knockout Mice."Molecular and cellular biology, 1098-5549 (Electronic).

Ruela-de-Sousa, R. R., K. C. Queiroz, et al. (2011). "Reversible phosphorylation in haematological malignancies: potential role for protein tyrosine phosphatases in treatment?"Biochim Biophys Acta, 18062: 287-303 0006-3002 (Print).

Ruvolo, P. P., Y. H. Qui, et al. (2011). "Low expression of PP2A regulatory subunit B55alpha is associated with T308 phosphorylation of AKT and shorter complete remission duration in acute myeloid leukemia patients."Leukemia, 1476-5551 (Electronic).

Sablina, A. A., W. Chen, et al. (2007). "The tumor suppressor PP2A Abeta regulates the RalA GTPase."Cell, 1295: 969-982 0092-8674 (Print). 
Sablina, A. A. and W. C. Hahn (2008). "SV40 small T antigen and PP2A phosphatase in cell transformation."Cancer Metastasis Rev, 272: 137-146 0167-7659 (Print).

Sablina, A. A., M. Hector, et al. (2010). "Identification of PP2A complexes and pathways involved in cell transformation."Cancer Res, 7024: 10474-10484 1538-7445 (Electronic).

Salas, A., S. Ponnusamy, et al. (2011). "Sphingosine kinase-1 and sphingosine 1-phosphate receptor 2 mediate Bcr-Abl1 stability and drug resistance by modulation of protein phosphatase 2A."Blood, 11722: 5941-5952 1528-0020 (Electronic).

Samanta, A. K., S. N. Chakraborty, et al. (2009). "Jak2 inhibition deactivates Lyn kinase through the SET-PP2A-SHP1 pathway, causing apoptosis in drug-resistant cells from chronic myelogenous leukemia patients."Oncogene, 2814: 1669-1681 1476-5594 (Electronic).

Sarbassov, D. D., D. A. Guertin, et al. (2005). "Phosphorylation and regulation of Akt/PKB by the rictor-mTOR complex."Science, 3075712: 1098-1101 1095-9203 (Electronic).

Seamon, K. and J. W. Daly (1981). "Activation of adenylate cyclase by the diterpene forskolin does not require the guanine nucleotide regulatory protein."J Biol Chem, 25619: 9799-9801 0021-9258 (Print).

Seamon, K. B., W. Padgett, et al. (1981). "Forskolin: unique diterpene activator of adenylate cyclase in membranes and in intact cells."Proc Natl Acad Sci U S A, 786: 3363-3367 0027-8424 (Print).

Sears, R., F. Nuckolls, et al. (2000). "Multiple Ras-dependent phosphorylation pathways regulate Myc protein stability."Genes Dev, 1419: 2501-2514 0890-9369 (Print).

Seeling, J. M., J. R. Miller, et al. (1999). "Regulation of beta-catenin signaling by the B56 subunit of protein phosphatase 2A."Science, 2835410: 2089-2091.

Shi, W., C. Sun, et al. (2004). "GADD34-PP1c recruited by Smad7 dephosphorylates TGFbeta type I receptor."J Cell Biol, 1642: 291-300 0021-9525 (Print).

Shouse, G. P., Y. Nobumori, et al. (2010). "A B56gamma mutation in lung cancer disrupts the p53-dependent tumor-suppressor function of protein phosphatase 2A."Oncogene, 2927: 3933-3941 1476-5594 (Electronic).

Sontag, E., S. Fedorov, et al. (1993). "The interaction of SV40 small tumor antigen with protein phosphatase $2 \mathrm{~A}$ stimulates the map kinase pathway and induces cell proliferation."Cell, 755: 887-897 0092-8674 (Print).

Soo Hoo, L., J. Y. Zhang, et al. (2002). "Cloning and characterization of a novel $90 \mathrm{kDa}$ 'companion' auto-antigen of p62 overexpressed in cancer."Oncogene, 2132: 50065015.

Stevens, I., V. Janssens, et al. (2003). "Identification and characterization of B"-subunits of protein phosphatase $2 \mathrm{~A}$ in Xenopus laevis oocytes and adult tissues."Eur J Biochem, 2702: 376-387 0014-2956 (Print).

Strack, S., D. Chang, et al. (1999). "Cloning and characterization of B delta, a novel regulatory subunit of protein phosphatase 2A."FEBS Lett, 4603: 462-466 0014-5793 (Print).

Strack, S., J. T. Cribbs, et al. (2004). "Critical role for protein phosphatase 2A heterotrimers in mammalian cell survival."J Biol Chem, 27946: 47732-47739 0021-9258 (Print).

Suganuma, M., H. Fujiki, et al. (1988). "Okadaic acid: an additional non-phorbol-12tetradecanoate-13-acetate-type tumor promoter."Proc Natl Acad Sci U S A, 856: 17681771 0027-8424 (Print). 
Suzuki, K. and K. Takahashi (2003). "Reduced expression of the regulatory A subunit of serine/threonine protein phosphatase 2A in human breast cancer MCF-7 cells."Int J Oncol, 235: 1263-1268 1019-6439 (Print).

Taetle, R. and S. Li-en (1984). "Further studies on mechanisms of abnormal prostaglandin response by chronic myelogenous leukaemia granulocyte/macrophage progenitors."Leuk Res, 85: 833-842 0145-2126 (Print).

Takabe, K., S. W. Paugh, et al. (2008). "'Inside-Out" Signaling of Sphingosine-1-Phosphate: Therapeutic Targets."Pharmacol Rev, 602: 181-195.

Takagi, Y., M. Futamura, et al. (2000). "Alterations of the PPP2R1B gene located at 11q23 in human colorectal cancers."Gut, 472: 268-271.

Tamaki, M., T. Goi, et al. (2004). "PPP2R1B gene alterations inhibit interaction of PP2AAbeta and PP2A-C proteins in colorectal cancers."Oncol Rep, 113: 655-659.

Tartaglia, M. and B. D. Gelb (2005). "Germ-line and somatic PTPN11 mutations in human disease."Eur J Med Genet, 482: 81-96 1769-7212 (Print).

Tartaglia, M., S. Martinelli, et al. (2004). "Genetic evidence for lineage-related and differentiation stage-related contribution of somatic PTPN11 mutations to leukemogenesis in childhood acute leukemia."Blood, 1042: 307-313 0006-4971 (Print).

Tartaglia, M., S. Martinelli, et al. (2005). "Somatic PTPN11 mutations in childhood acute myeloid leukaemia."Br J Haematol, 1293: 333-339 0007-1048 (Print).

Tartaglia, M., C. M. Niemeyer, et al. (2003). "Somatic mutations in PTPN11 in juvenile myelomonocytic leukemia, myelodysplastic syndromes and acute myeloid leukemia."Nat Genet, 342: 148-150 1061-4036 (Print).

Uzunoglu, S., R. Uslu, et al. (1999). "Augmentation of methylprednisolone-induced differentiation of myeloid leukemia cells by serine/threonine protein phosphatase inhibitors."Leuk Res, 235: 507-512 0145-2126 (Print).

Vanhaesebroeck, B. and D. R. Alessi (2000). "The PI3K-PDK1 connection: more than just a road to PKB."Biochem J, 346 Pt 3: 561-576 0264-6021 (Print).

Vogelstein, B., D. Lane, et al. (2000). "Surfing the p53 network."Nature, 4086810: 307-310 0028-0836 (Print).

Wang, J. and W. Li, Li, L., Yu, X., Jia, J., Chen, C. (2011). "CIP2A is over-expressed in acute myeloid leukaemia and associated with HL60 cells proliferation and differentiation."Int J Lab Hematol, 333: 290-298 1751-553X (Electronic).

Wang, L., J. E. Fortney, et al. (2004). "Stromal cell protection of B-lineage acute lymphoblastic leukemic cells during chemotherapy requires active Akt."Leuk Res, 287: 733-742 0145-2126 (Print).

Wang, P. Y., P. Liu, et al. (2003). "A cholesterol-regulated PP2A/HePTP complex with dual specificity ERK1/2 phosphatase activity."Embo J, 2211: 2658-2667.

Wang, S. S., E. D. Esplin, et al. (1998). "Alterations of the PPP2R1B gene in human lung and colon cancer."Science, 2825387: 284-287.

Wei, S., X. Chen, et al. (2009). "A critical role for phosphatase haplodeficiency in the selective suppression of deletion 5q MDS by lenalidomide."Proc Natl Acad Sci U S A, 10631: 12974-12979 1091-6490 (Electronic).

Willert, K., C. Y. Logan, et al. (1999). "A Drosophila Axin homolog, Daxin, inhibits Wnt signaling."Development, 12618: 4165-4173 0950-1991 (Print). 
Xiao, L., L. L. Gong, et al. (2010). "Protein phosphatase-1 regulates Akt1 signal transduction pathway to control gene expression, cell survival and differentiation."Cell Death Differ, 179: 1448-1462 1476-5403 (Electronic).

$\mathrm{Xu}$, X. H., J. Ou-Yang, et al. (2008). "[Effect of okadaic acid on differentiation of NB4 and MR2 cells induced by all-trans retinoic acid]."Zhonghua Xue Ye Xue Za Zhi, 296: 379383 0253-2727 (Print).

Yamamoto, H., T. Hinoi, et al. (2001). "Inhibition of the Wnt signaling pathway by the PR61 subunit of protein phosphatase 2A."J Biol Chem, 27629: 26875-26882.

Yamamoto, M., Y. Suzuki, et al. (1999). "Expressions of four major protein Ser/Thr phosphatases in human primary leukemic cells."Leukemia, 134: 595-600 0887-6924 (Print).

Yan, Z., S. A. Fedorov, et al. (2000). "PR48, a novel regulatory subunit of protein phosphatase 2A, interacts with Cdc6 and modulates DNA replication in human cells."Mol Cell Biol, 203: 1021-1029 0270-7306 (Print).

Yang, J., J. Wu, et al. (2003). "PP2A:B56epsilon is required for Wnt/beta-catenin signaling during embryonic development."Development, 13023: 5569-5578.

Yang, Y., X. Q. Li, et al. (2011). "[Influence of PP2A Activator on Proliferation of HL-60 Cells and Analysis of PP2A Activity Changes in Patients with Acute Myeloid Leukemia.]."Zhongguo Shi Yan Xue Ye Xue Za Zhi, 193: 594-597 1009-2137 (Print).

Yeh, E., M. Cunningham, et al. (2004). "A signalling pathway controlling c-Myc degradation that impacts oncogenic transformation of human cells."Nat Cell Biol, 64: 308-318.

Yin, T., Y. L. Wu, et al. (2004). "Combined effects of As4S4 and imatinib on chronic myeloid leukemia cells and BCR-ABL oncoprotein."Blood, 10413: 4219-4225 0006-4971 (Print).

Yu, J., A. Boyapati, et al. (2001). "Critical role for SV40 small-t antigen in human cell transformation."Virology, 2902: 192-198.

Yuan, H., T. Veldman, et al. (2002). "Simian virus 40 small tumor antigen activates AKT and telomerase and induces anchorage-independent growth of human epithelial cells."J Virol, 7621: 10685-10691.

Yuksel, S., G. Saydam, et al. (2002). "Arsenic trioxide and methylprednisolone use different signal transduction pathways in leukemic differentiation."Leuk Res, 264: 391-398 0145-2126 (Print).

Zemann, B., B. Kinzel, et al. (2006). "Sphingosine kinase type 2 is essential for lymphopenia induced by the immunomodulatory drug FTY720."Blood, 1074: 1454-1458 0006-4971 (Print).

Zhang, Q., P. N. Raghunath, et al. (2000). "Lack of phosphotyrosine phosphatase SHP-1 expression in malignant T-cell lymphoma cells results from methylation of the SHP-1 promoter."Am J Pathol, 1574: 1137-1146 0002-9440 (Print).

Zhang, W., J. Yang, et al. (2009). "PR55alpha, a regulatory subunit of PP2A, specifically regulates PP2A-mediated beta-catenin dephosphorylation."J. Biol. Chem.: M109.013698.

Zhao, J. J., O. V. Gjoerup, et al. (2003). "Human mammary epithelial cell transformation through the activation of phosphatidylinositol 3-kinase."Cancer Cell, 35: 483-495.

Zheng, H., Y. Chen, et al. (2011). "Expression and distribution of PPP2R5C gene in leukemia."J Hematol Oncol, 4: 21 1756-8722 (Electronic). 
Zhou, B., Z. X. Wang, et al. (2002). "The specificity of extracellular signal-regulated kinase 2 dephosphorylation by protein phosphatases."J Biol Chem, 27735: 31818-31825 00219258 (Print).

Zhou, J., H. T. Pham, et al. (2003). "Characterization of the Aalpha and Abeta subunit isoforms of protein phosphatase 2A: differences in expression, subunit interaction, and evolution."Biochem J, 369Pt 2: 387-398.

Zolnierowicz, S., C. Csortos, et al. (1994). "Diversity in the regulatory B-subunits of protein phosphatase 2A: identification of a novel isoform highly expressed in brain."Biochemistry, 3339: 11858-11867 0006-2960 (Print). 


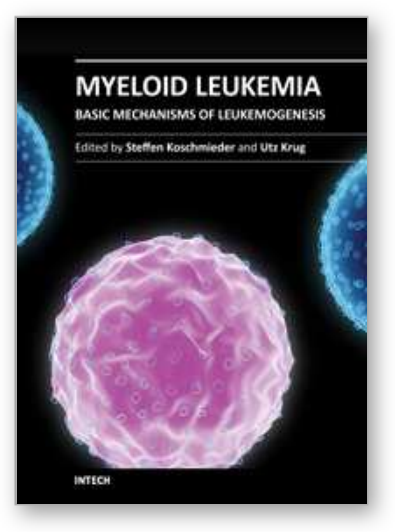

\author{
Myeloid Leukemia - Basic Mechanisms of Leukemogenesis \\ Edited by Dr Steffen Koschmieder
}

ISBN 978-953-307-789-5

Hard cover, 484 pages

Publisher InTech

Published online 14, December, 2011

Published in print edition December, 2011

The current book comprises a series of chapters from experts in the field of myeloid cell biology and myeloid leukemia pathogenesis. It is meant to provide reviews about current knowledge in the area of basic science of acute $(A M L)$ and chronic myeloid leukemia $(C M L)$ as well as original publications covering specific aspects of these important diseases. Covering the specifics of leukemia biology and pathogenesis by authors from different parts of the World, including America, Europe, Africa, and Asia, this book provides a colorful view on research activities in this field around the globe.

\title{
How to reference
}

In order to correctly reference this scholarly work, feel free to copy and paste the following:

Amanda M. Smith, Kathryn G. Roberts and Nicole M. Verrills (2011). Ser/Thr Phosphatases: The New Frontier for Myeloid Leukemia Therapy?, Myeloid Leukemia - Basic Mechanisms of Leukemogenesis, Dr Steffen Koschmieder (Ed.), ISBN: 978-953-307-789-5, InTech, Available from:

http://www.intechopen.com/books/myeloid-leukemia-basic-mechanisms-of-leukemogenesis/ser-thrphosphatases-the-new-frontier-for-myeloid-leukemia-therapy-

\section{INTECH}

open science | open minds

\section{InTech Europe}

University Campus STeP Ri

Slavka Krautzeka 83/A

51000 Rijeka, Croatia

Phone: +385 (51) 770447

Fax: +385 (51) 686166

www.intechopen.com

\section{InTech China}

Unit 405, Office Block, Hotel Equatorial Shanghai

No.65, Yan An Road (West), Shanghai, 200040, China

中国上海市延安西路65号上海国际贵都大饭店办公楼 405 单元

Phone: +86-21-62489820

Fax: $+86-21-62489821$ 
(C) 2011 The Author(s). Licensee IntechOpen. This is an open access article distributed under the terms of the Creative Commons Attribution 3.0 License, which permits unrestricted use, distribution, and reproduction in any medium, provided the original work is properly cited. 